air-permeability of wrappers for margarine. The permeability of rubber sealing rings to gases and volatile substances is a cause of deterioration in meat and fish pastes, and the most desirable formulation for such rubber rings is being sought in collaboration with the manufacturers.

1 See Nature, 168, 1108 (1951).

2 Oil and Soap, 21, 293 (1944).

${ }^{3}$ Int. Choc. Rev., 6, 350 (1951).

4 Nature, 175, 818 (1955).

\section{RADIATION CHEMISTRY OF SOLUTIONS}

$\mathrm{T}$ HE fifth annual meeting of the Société de Chimie Physique was held in Paris during May 31-June 3, the subject of the meeting being the chemical effects of ionizing radiation. It was organized by Prof. G. Emschwiller and was attended by chemists and physicists from Europe, the United States and the U.S.S.R.

Radiation chemistry is complicated by the fact that the primary events are confined to the tracks of the ionizing particles. It was pointed out that in aqueous solutions the yield varies with radiation quality, the principal change occurring in the range 6.5-25 keV./ $\mu$ mean linear energy transfer of the radiation. On the assumption that only those parts of the ionizing tracks where the linear energy transfer is greater than $25 \mathrm{keV} . / \mu$ are effective, and taking $\delta$-rays into account, a curve for the efficiency of different radiations has been calculated which is in good agreement with the experimental data for the molecular hydrogen yield (L. H. Gray). A tentative mathematical picture was given of the kinetics of radicals formed in a track (J. L. Magee). With increasing intensity, the tracks overlap and the kinetics of homogeneous solutions apply. This change was demonstrated using diphenylpicryl bydrazine in chloroform (A. Chapiro). There is a possibility that excited water molecules play a part in the indirect effects in dilute solutions (J. Weiss). However, the strict proportionality of fluorescence and sodium salicylate concentration in an aqueous solution exposed to $\alpha$-radiation suggests the absence of indirect excitation of the solute (N. Miller).

The most useful system for the chemical measurement of dose is still a solution of $0.001 M$ ferrous ions in $0 \cdot 1 M$ sulphuric acid. Several recent determinations for $\mathrm{X}$-rays and $\beta$-rays have all favoured a value close to $G_{\mathrm{Fe}^{+++}}=15.5$ molecules per $100 \mathrm{eV}$. (N. Miller ; A. J. Swallow ; M. Cottin). An accurate determination has been carried out with $2 \mathrm{MeV}$. electrons and gives $G_{\mathrm{Fe}^{+++}}=\mathbf{1 5} \cdot 45 \pm 0.11$ (R. H. Schuler and A. O. Allen, reported by N. Miller). The kinetics for the oxidation of $10^{-3} M$ ferrous ions in $0 \cdot 1 M$ sulphuric acid are fairly well understood, but are totally inadequate to explain the high yield $\mathrm{GFe}_{\mathrm{Fe}^{+++}}=63$ obtained in aerated solutions of $2 \times 10^{-2} M$ ferrous ions in $4 M$ sulphuric acid (Proskurnin, quoted by S. S. Medvedev). The sensitivity of yield to the presence of impurities was demonstrated with the $\mathrm{Fe}_{\Theta}++$ system (N. Miller ; C. Vermeil). For the measurement of exceptionally high doses, oxalic acid was recommended (I. Draganic). The measurement of dose by the ionization method depends upon the energy $W$ required to form one ion-pair in air. Recent measurements with polonium $\alpha$-rays give values close to $W=\mathbf{3 5 . 5} \mathrm{eV}$., in agreement with older data. Now results for fast electrons obtained from a comparison of absolute countingrates and ionization measurements of sodium-24, cobalt-60, gold-198, iodine-131 and phosphorus-32 lead to a value of $W=34 \pm 1 \mathrm{eV}$. in air, differing slightly from $W=32.5 \mathrm{eV}$., the value widely used in radiological work (W. Emery, reported by L. H. Gray).

It was generally agreed that the initial products in the radiolysis of water are the free hydrogen and hydroxyl radicals and the molecular products hydrogen and hydrogen peroxide. The mechanism giving rise to the formation of the molecular products is not understood, but evidently it occurs in those parts of the tracks where the linear energy transfer is very high. The yields of molecular hydrogen are less affected than the yields of hydrogen peroxide by the presence of various solutes (M. Lefort and $\mathbf{M}$. Cottin). New light was thrown on these processes by studies of radiation-induced polymerization and of the production of hydrogen peroxide in gas-free aqueous solutions of acrylonitrile. Both the monomer and polymer are inert to hydrogen peroxide, but readily combine with hydrogen and hydroxyl radicals. The yield of hydrogen peroxide varies with monomer concentration. It is at a maximum at $10^{-2} M$ and drops by a factor of 6 at the highest monomer concentration used, $0.5 M$, when the monomer reacts with precursors of hydrogen peroxide even in the densest parts of the tracks (E. Collinson, F. S. Dainton and G. F. MeNaughton). No similar demonstration of precursors of molecular hydrogen has yet been made. It might be formed directly from one water molecule, but the dependence of the yield on the linear energy transfer suggests a recombination process (M. Haĩssinsky; G. Stein; M. Magat). Oxygen-18 has been used in a study of the production and decomposition of hydrogen peroxide by radiation (E. J. Hart, S. Gordon and D. A. Hutchinson).

Some of the aqueous solutions investigated are of biochemical interest. Irradiation of phosphoric acid esters of the homologous series of methyl to amyl alcohols shows that the larger molecules are more stable. The main products of decomposition are inorganic phosphate, acyl phosphate, aldehyde and hydrogen peroxide. All solutions show an aftereffect if irradiated in the presence of oxygen. Analogous results with solutions of mononucleotides were reported (R. W. Wilkinson and T. F. Williams; G. Scholes; M. Daniels). Radiation effects on catalase in dilute aqueous solution show that quantitative results depend to a very large extent on the purity of the enzyme preparation. The enzyme is inactivated by hydroxyl radicals and not by hydrogen radicals as has been previously assumed (W. M. Dale and C. Russell; P. Bonet-Maury and F. Patti; H. C. Sutton, quoted by L. H. Gray). In contrast, reduction processes occur in solutions of methylene blue, coenzyme I and diphosphopyridine nucleotide (G. Stein ; A. J. Swallow).

Irradiation of aqueous solutions of polyvinylpyrrolidine and other water-soluble polymers leads to degradation if the concentration is less than 0.3 per cent, and to cross-linking if more than 1 per cent (A. Charlesby and P. A. Alexander). The mechanism of cross-linking, however, is not yet understood (A. Henglein; Y. Landler). Irradiation of air-free solutions of methacrylic acid leads to polymerization which continues after the end of the exposure. The resulting polymer, dried and exposed to air for several hours, can still initiate polymerization in new unirradiated monomer solutions (M. Fox and P. A. 
Alexander). Similarly, irradiated dry polymers can initiate polymerization in their own or different monomer solutions, even months after the exposure, thereby forming so-called graft polymers. These show a mixture of the physical properties of the parent substances (A. Chapiro; M. Magat). The reactions of diphenylpicryl hydrazine have been studied in great detail, showing that substitution occurs in the $p$-position of the phenyl groups (A. Henglein; W. Wild). Irradiated solutions of diphenylpicryl hydrazine show an after-effect lasting for several weeks. Some discrepancies between the experiments with this substance in Britain, France and Germany seem to have been due to differences in analytical procedures and conditions of irradiation (W. Wild; A. Chapiro; A. Henglein). The loss of colour of diphenylpicryl hydrazine, irradiated in mixtures of organic solvents, does not follow a simple additive law, indicating energy transfer from one solvent molecule to the other (A. Chapiro; S. S. Medvedev). Similar evidence of a non-additive effect has been observed in the luminescence of $p$-terphenyl induced by $\gamma$-irradiation in mixtures of benzene and cyclohexane (M. Burton, P. J. Berry and S. Lipsky). The use of radiation as an energy source in preparatory organic chemistry was demonstrated in halogenation reactions of aromatic compounds and in the synthesis of methylene blue and other organic substances (D. E. Harmer, J. J. Martin and L. Anderson; J. Loiseleur).

Many of those who attended both this meeting and the Faraday Society Discussion on radiation chemistry in Leeds in 1952 felt that in Paris there was less controversy about possible radical intermediates, most of the new results falling into line with accepted schemes of radical formation and reaction. Even the concept of the 'molecular yield' which has had considerable prominence showed signs of giving way to interpretation in terms of these schemes.

\section{EBBERT}

P. HOWARD-FIANDERS

\section{POLAROGRAPHIC INSTRUMENTATION}

\section{FIRST SYMPOSIUM OF THE POLAROGRAPHIC SOCIETY}

$\mathrm{B}^{\mathrm{Y}}$ $Y$ invitation of Prof. F. S. Dainton, the first symposium of the Polarographic Society was held in the Chemistry Department of the University of Leeds on May 25. In its emphasis on the design of polarographic instruments, this meeting is believed to have been the first of its kind to be held in Great Britain. After Prof. Dainton had extended a welcome to the Society, the chairman mentioned the steps leading to its recent formation and briefly outlined its objects.

In most cases, those reading papers explained the essential principles of the circuits employed in their instruments. C. Wontner described a simple manual polarograph and demonstrated its use in obtaining current/voltage curves. These can be plotted with surprising speed because of the semi-automatic location of the voltage scale in a series of $10-\mathrm{mV}$. steps. By virtue of a magic-eye null-point detector, the manual polarograph described by G. O. Jolliffe measures the true maximum current and so eliminates assumptions about the detector's equation of motion.
This instmment is also of interest to the polarographic research worker in that it contains facilities for measuring both current and voltage potentiometrically.

A pen-recording polarograph, which possesses a photovoltaic amplifier of very short time-constant, was described by E. A. Wood and Mrs. B. Lamb. The design of an associated condenser/resistance differentiating unit for use in derivative polarography was also explained. G. L. Young dealt with a penrecording instrument involving a different type of amplifier and paid special attention to the theoretical aspects of an attachment which enables the instrument to record true derivative peaks by the a.c. polarographic method of Breyer and Gutmann.

After dealing with the rather differently shaped waves encountered in cathode-ray polarography, G. F. Reynolds gave an outline of the theory by explaining the equations of Randles and Sevcik. Apart from being more sensitive than conventional instruments, the Chemical Inspectorate, Randlestype, single-sweep polarograph can also be operated with greater speed and simplicity. In its resolution of closely spaced steps and compensation for a preceding step, the instrument's normal performance is between that of the 'conventional' and the 'derivative' polarograph. However, the incorporation of a derivative circuit enables it where necessary to achieve the resolution of the derivative polarograph together with a much greater sensitivity. $\mathrm{Mr}$. Reynolds expressed the view that, in general, the sensitivity and applicability of the cathode-ray polarograph are equal to that of the square-wave polarograph at its present stage of development. The design principles of a single-sweep cathode-ray polarograph were then given by $\mathrm{H}$. W. Rowe-Leete, who also dealt with the electronics in terms of block diagrams.

By way of a contrast to these purely instrumental contributions, Mrs. N. Luthy read a paper on the application of the polarograph to pyrimidine chemistry, with particular reference to the detection of the $-\mathrm{S}-\mathrm{S}-$ bond.

A. I. GLenN

\section{LIBRARY RESOURCES IN THE MANCHESTER AREA}

A CONFERENCE on library resources for industry and commerce in the Manchester area was held in Manchester on March 10 by the Northern Branch of Aslib. The speakers were Mr. D. I. Colley, Manchester City librarian; Mr. V. D. Freedland, information officer of the British Hat and Allied Feltmakers Research Association; Mr. L. L. Ardern, librarian of the Manchester College of Technology; and Mr. R. Brightman, bibliographer of the Dyestuffs Division, Imperial Chemical Industries, Ltd.

In his survey of the services provided by the City Library, Mr. Colley emphasized their diversity. The main point is that these services have to meet the varied need of the rate-payers who pay for them. The commercial and technical libraries, while important and highly developed, are but two sections. This dependence on local finance necessarily limits developments. This is unfortunate, he said, because a census taken during 1954 showed that some 40 per cent of the users of the reference libraries were not rate-payers. Moreover, an analysis of this 40 per cent showed that Manchester is not only providing a 